\title{
Juvenile Delinquency: A Need to Multiple Explanations and Interventions
}

\author{
Gamachu Gishe Badasa1 ${ }^{*}$, Abdurehman Gemeda², Burash Elemo Gaduda ${ }^{3}$, Bezabih Wondimu ${ }^{4}$ \\ ${ }^{1}$ Department of Psychology, College of Education and Behavioral Studies, Madda Walabu University, Bale Robe, Ethiopia \\ ${ }^{2}$ Institute of Leadership and Good Governance, Ethiopian Public Service University, Addis Abba, Ethiopia \\ ${ }^{3}$ Department of Adult Education and Community Development, College of Education and Behavioral Studies, Madda Walabu \\ University, Bale Robe, Ethiopia \\ ${ }^{4}$ Department of Educational Planning and Management, College of Education and Behavioral Studies, Madda Walabu University, \\ Bale Robe, Ethiopia \\ Email: `gamachugishe@gmail.com, abdurehmangemeda59@gmail.com, bezabih19@yahoo.com
}

How to cite this paper: Badasa, G.G., Gemeda, A., Gaduda, B.E. and Wondimu, B. (2019) Juvenile Delinquency: A Need to Multiple Explanations and Interventions. Open Access Library Journal, 6: e5904. https://doi.org/10.4236/oalib.1105904

Received: November 6, 2019

Accepted: December 9, 2019

Published: December 12, 2019

Copyright $\odot 2019$ by author(s) and Open Access Library Inc.

This work is licensed under the Creative Commons Attribution International License (CC BY 4.0).

http://creativecommons.org/licenses/by/4.0/

\begin{abstract}
To come up with complete understanding about the root causes of juvenile delinquency, explanations were given from different perspectives. Hence, psychologists, sociologists, political scientists and economists provide several reasons for causes of inappropriate behaviors. These are peer group pressure, family, community, and status differences among the different classes that seek to explain this phenomenon. The findings suggested that no single intervention is effective to rehabilitate the target group. Indeed, because of the fact that its origins are too much complicated so the interventions should be given at individual, family, school and community levels.
\end{abstract}

\section{Subject Areas}

Education, Psychology, Sociology

\section{Keywords}

Delinquency, Intervention, Juvenile, Multiple, Theory, Youth

\section{Introduction and Background}

Juvenile delinquency refers to violations of the criminal law by minors. Most states legally define individuals as minors until they turn 18 . This does not mean that, juvenile delinquents are viewed simply as young criminals [1]. Moreover, [2] wrote that youth delinquency is culturally relative as a behavior varies across countries. Therefore, what may be treated as delinquent behavior in one country 
or state may not necessarily be treated as such in another.

As it had been stated in [3] convention on the right of juveniles, accused juveniles shall be separated from adult prisoners and brought at court immediately. Hence, the justice system views juvenile offenders as immature in the sense that they are less capable of appreciating the consequences of their actions, less able to exercise self-control, and more easily lead astray by others [1]. Therefore, this article focuses on the main bases of adolescents' criminal behaviors and its interventions methods.

\subsection{The Rationality behind Choosing This Topic}

Juveniles are the most important nun of human beings who should be given emphasis in all aspects for the continuation of generation. They are too sensitive and always present on the pitch of trust and mistrust based on the act of different stakeholders that contribute their effort on them. If the stakeholders devoted to them positively they will grow with positive self-image and personality and will be free of malpractice and crime related issue. These help them to trust their caregivers and their environment. However, if different concerned bodies are devoted to them negatively, they will grow with negative self-image and personality and become victim of malpractice, crime, become addictive to different drugs and etc.

In spite of the fact that, juveniles are mistreating currently. A number of juveniles' home is street of different cities and towns. Even those who are at home with their families and at school are not handling carefully. Labeling the juveniles is becoming usual activities and is not taken as humiliation currently. Therefore, this article focuses on the main bases of adolescents' criminal behaviors and its interventions methods.

\subsection{Significance of Choosing This Topic}

Investing on juveniles is investing on future fate of one country. For this reason, this topic has very important significance for families because it enables them to have crime and juveniles' delinquency free generation. It also helps communities to be free of delinquency related to juveniles. In addition to this, it will help policy makers to give more attention to issue related to juveniles in all aspects.

\subsection{Conflict Theory and Delinquency}

Study suggested that conflict theory is primarily concerned with the concept of power and has its roots in rebellion, class conflict, and the philosophy of Marxism [4]. For instance, [5] reaches the conclusion that delinquency is a product of conflicts over the distribution of resources and the illegitimacy of such a distribution especially as it affects the poor and the groups that seek to organize and bring conflict out into the open. Similarly, Jacob [6] maintains that the relative differences in income among the different classes in society are the leading causes of delinquent behaviors. 
Furthermore, [5] illustrates that Marx's theoretical approach proposed conceptual stages while explaining the root causes of delinquent behaviors. These are:

- although social systems reveal interdependence of certain units and groups, these interrelations always reveal conflicts of interest.

- latent conflicts of interest will eventually lead to overt and violent conflict among social groups in a system.

- these conflicts will eventually lead to the dominant and subjugated segments of a system's becoming polarized.

- the more polarized the dominant and subjugated, the more violent the ensuing conflict will be. The more violent the conflict, the greater will be the structural change of the system and the redistribution of scarce resources.

- this reorganization once again creates conditions of conflicting interest between the new dominant and subjugated classes, which will set into motion the inevitable processes of class conflict, polarization, violence, and system reorganization.

\subsection{Labeling Theory and Delinquency}

[7] underlines that delinquent act is caused by a number of factors with the main reason for repeat offending being the label delinquent appended becomes incorporated into the youth's cognition of himself or herself. As a result, the label alters the target's self-image so that she or he construes herself or himself as a delinquent and therefore will act accordingly. Likewise, [8] found that delinquency results due to individual exposure to the communities and it is likely that every person can commit criminal acts. This scholar also explained that youth who are labeled as delinquents might hold these as self-fulfilling prophecies believing the labels that others assign to them thereby acting as the labels.

Furthermore, labeling theory affiliated researchers were tried to explain the development of crime and delinquent behaviors from many perspectives. These are; the socio-historical development of deviant labels, the application of labels to certain types of people in specific times and places, and the symbolic and practical consequences of the labeling process [9].

As a result, offenders may encounter social obstacles that effectively block them from the benefits of conventional society because of serious stigma [10]. It was researched that difficulty obtaining meaningful work, earning a high school diploma and lack of participatory civic life because of a criminal record more escalate maladaptive behavior among at risky groups [10].

\subsection{Economic Theory of Crime and Delinquency}

Economists argue that crime is a result of individuals' making choices between using their scarce resources of time and effort in legitimate or in illegitimate activities. A key assumption is that when making these choices, individuals are rational and choose the best option based on the available information and re- 
sources [6]. Economists measure the profit from crime in terms of monetary benefits alongside physical, psychic, and other benefits. The costs of crime include the risk of detection, apprehension, and conviction and the severity of punishment [6]. Besides, [6] underlines the link between crime and socioeconomic factors. For example, poverty, unemployment, class structure and inequality whereby an increase in these factors leads to increased crime.

\subsection{General Strain Theory and Delinquency}

[11] highlights that juveniles may engage in delinquency when they experience pressure or stress. With regard to the causes of delinquent behaviors, [12] outlines many conditions under which it causes to happen:

- If there is parental rejection, in which parents show little love or affection for their children, provide little support to them, and often display hostility toward them.

- Likewise, if there is supervision that is erratic, excessive, and/or

- Any peer abuse, which includes insults, ridicule, gossip, threats, attempts to coerce, and physical assaults.

- The failure to achieve selected goals, including excitement, high levels of autonomy, masculine status, and much money in a short period.

- Residence in economically deprived communities, which is associated with exposure to a host of strains, including victimization, family and school problems, and peer abuse.

- Homelessness.

\subsection{Social Control Theories and Delinquency}

According to this theory, delinquency occurs when an individual's bond through specified control mechanisms with society is weak or diminished. Specifically, when a person is connected to conventional society through attachment, commitment, belief, and involvement he or she is more likely to accept conventional norms, participate in conventional activities, and therefore behave in a desirable manner [13].

To this end, [14] reaches the conclusion that the breakdown of peoples' economy, culture and many other institutions lead to the deterioration of social ties. Thus, when family members are separated and do not connect, they are in a state of disorganization and are likely to drift toward other supporting systems meaning peers. The adolescent who is not getting support at home will avoid mainstream norms or systems and move towards nonconventional systems because of the support they may be receiving from such systems [13].

[15] points out that all individuals are strongly motivated to engage in delinquency, since delinquency is often the easiest way to get what he/she wants. For example, it is easier for offenders to steal money than to work for it.

\subsection{Psychoanalysis Theory and Delinquency}

In general, according to Freudian theory of psychoanalysis, psychological dis- 
turbance in the youth began in early childhood [7]. [16] argues that abstract thinking and behavioral regulation are inherent in an individual. Furthermore, [7] wrote the Freudian notion that the internal conflicts among the structure of personalities ID, Ego and Superego lead to delinquency. This scholar also concludes that delinquency is a manifestation of underlying constructs comprising a person's psychological framework, including Freud's conceptualizations of the conscious and unconscious. Delinquent behavior occurs because of imbalance between these three parts of our personality and is thought to be a symbolic way of meeting our unconscious needs [16].

\subsection{Social Learning Theories and Delinquency}

According to social learning theories, both adaptive and maladaptive behaviors are learned from significant others. The level of exposure to delinquent peers influences individuals' definitions regarding what behaviors are good or bad. Delinquent peers also serve as models that juveniles imitate. Individuals' behaviors are then differentially reinforced which affects whether delinquent behaviors persist [11]. The same techniques may work for delinquency.

[17] goes further that youth more likely follow their models via social modelling. For example, in their study it was found that teenagers who have parents who abuse alcohol or engage in criminal activities could often develop similar attitudes and behaviors. Moreover, [18] assumptions seem to be realistic that children living in antisocial families, large family size, poor parental supervision, parental conflict, and disrupted families environments are at increased risk for offending because their parents may teach them to be delinquent via their words and/or actions. The work of [17] also strengthens the results of, [18] that data received from police officers were also revealed adolescents who were frequently in trouble with the law often came from families with criminal histories.

From a behavioral psychology perspective, peer approval, social modelling, enjoyment, escape, and status were identified as reinforcing adolescent delinquency and problem drinking behaviors. For example, enjoyment positively reinforces crime and alcohol use in that it incites fun, whereas escape negatively reinforces crime or alcohol use as engagement in these activities helps the teenager avoid uncomfortable feelings or events [17].

\section{Intervention Methods}

\subsection{Educational Interventions}

There is a linked between poor school achievement and potential higher likelihood for involvement in delinquency in subsequent years [19]. Furthermore, [12] illustrated that negative secondary school experiences, including low grades, negative relations with teachers for example if the teachers treat the juvenile unfairly, belittle or humiliate the juvenile and the experience of school as boring escalates the chance of at risk group taking part on antisocial behavior.

Indeed, there are diverse intervention methods used to rehabilitate delinquent 
youth at school. For example, [20] proposed multiple practical solution for this problem namely tutoring, enhancement of the cultural competence of teachers, and school wide changes to provide a more supportive and caring school climate. [19] also came to summarize that all public schools in every states are required to have special education programs and services for children whose behaviors interfere with academic performance. In order to bring behavioral change among violent youth [20] an alternative solution a macro level intervention that is community-wide intervention could mobilize students, teachers, parents, nonprofit organizations, businesses, and the media.

Researchers have stressed that; via youth mentoring program, schools can reduce its students' act of misbehavior. For instance, [18] are among notable researchers who used the big brothers/big sisters community-based mentoring program which involves pairing youth at risk for with adult volunteers who act as positive role models/mentors, provide children with ongoing support and encouragement, and engage in fun and/or educational activities with youth a few times a month.

Scholars such as [18] suggested useful solution to prevent child delinquency as early as possible, which is the preschool education programs should focus on intelligence and school achievement with the aim of scaling up cognitive, social and emotional development of the child. All we can say, [20] forwarded as teacher training curriculum should focus on teaching classroom wide positive management and discipline strategies and promoting social competence in the classroom.

\subsection{Community Level Interventions}

\section{Strengthening Weak Social Institutions}

According to [14] if there are weak social institutions where the individual grew up and living nowadays, it has a negative impact on economic conditions of that county and less capable of providing adequate supervision of both individuals and property in neighborhoods, resulting in higher rates of both property and violent crime. According to [10] the existence of serious social obstacles such as difficulty finding employment, ineligibility for student loans and exclusion from conventional social networks may affect their life-course orientation.

[14] noted that individuals will engage in criminal activity if it is perceived to be in their self-interest. Therefore, it is the responsibility of the society to monitor individuals so that it reduces the chances of crime being perceived as beneficial in some way and the negative consequences are more clearly understood.

[20] proposed a kind of intervention used by community psychologists in the context where there is poor tie among the community who owned weak economy as well. Thus, to make possible the social equalities, this scholar focused on social justice and empowerment to enhance levels of economic, social, and psychological resources for individuals and groups lacking power in society.

Subsequently, in response to fragile social relationship [20] strongly argued a 
need to organize community particularly at grassroots level to bring together citizens and community groups in low-income neighborhoods to pressure elected officials to allocate additional funding for basic needs. As [20] notes that, the formed group should be inclusive meaning it includes local government, business, human service agencies, citizen associations, and faith-based organizations.

In their social action and community change work, community psychologists often times work with a wide range of citizens, community groups, organizational staff and directors, and elected officials [20]. As [14] further observe that more efficacious communities are expected to have lower crime rates, because residents of those communities exhibit a greater level of social cohesion, reflected in the strength of social ties to each other and social institutions, as well as higher expectations of community sanction aimed at preventing problems from occurring.

\subsection{Family Level Interventions}

Peer approval may be particularly relevant for adolescents who are experiencing conflict at home or who have weakened attachments to prosocial role models, such as parents or teachers [17]. Furthermore, researchers on the area reported that low self-control which was due to poor parenting practices were found to be the primary cause of offending [21].

As a result, [18] proposed parental training programs seek to improve parents' ability to monitor their children's activities, clearly state rules and expectations for behavior, consistently and effectively discipline children using rewards and punishments, and build stronger emotional bonds with children. In harmony with the idea of [18], [21] capitalized parenting and schools do seem to play key roles in the development of self-control, with poor monitoring resulting in lower levels of it.

Again, [18] came to conclude that family based prevention programs target for change family characteristics and parenting practices that have been associated with delinquency. To illustrate how family level intervention results on their children healthy development, [18] have proposed as implified method which is visiting pregnant mothers at home alongside low-income and under employed mothers. Similarly, but more specifically [19] insisted that these efforts seek to minimize negative factors for the baby such as low birth weight, neurological impairments, and exposure to various environmental toxins. Scholars like [21] also recommended training package entitled as Basic Incredible Years Parenting Program to cultivate positive discipline strategies, effective parenting skills, strategies for coping with stress, and ways to strengthen children's social skills.

\subsection{Individual Level Interventions}

\section{Providing Assertive Training}


Among many more assertive trainings that rule out sever maladaptive behaviors of youth at risk, the followings are more common. These are self-efficacy and empowerment; cognitive skills; reducing negative emotional states; and managing identity shifts are some of life skill training suggested as a good way to avoid unhealthy behaviors [22].

Peer group is the most important social life during adolescence. Thus, in this context, they may seek to enhance their social, communication, decision-making, and self-efficacy skills in order to improve the group ability to positively relate to peers. However, at this stage he/she also negatively influenced by the norm of the group in the process of abiding to the dos and don'ts peers culture.

Example effective school-based interventions focusing on peer influences include the life skills training [18]. Consequently, [17] suggested peer programs to prevent delinquency by reducing the negative influence of delinquent peers via increasing the positive influence of prosocial peers.

Peer teaching as a method to battle against the development problem behavior in general and delinquency in particular are tested universally among students at schools and became effective. For example, [17] employed it through facilitating discussion and role play by asking students to practice with their classmates skills to avoid violent and provocative behaviors.

\section{Conclusion}

To come up with complete understanding about the root causes of juvenile delinquency, explanations were given from different perspectives. Psychologists, sociologists, political scientists and economists provide several reasons for causes of inappropriate behaviors. These are peer group pressure, family, community, and status differences among the different classes that seek to explain this phenomenon [6]. It was also suggested that no single intervention is effective to rehabilitate the target group. Indeed, because of the fact that its origins are too much complicated so the interventions should be given at individual, family, school and community levels.

\section{Recommendations}

1) Family should take care of their juveniles in their walk of life. Because their single activity has predominant effect on the future life of the juveniles.

2) Communities in general should play their own role in shaping juveniles. Because, the effect of single juvenile delinquency is not only bounded on his/her family. It will have meaning full effect on communities in general.

3) Policy makers should give due attention to the issue of juveniles. This is because if the issue of juveniles is not treated with policy formulation, it has substantiated outcome on its implementation.

\section{Conflicts of Interest}

There is no conflict of Interest. 


\section{References}

[1] Agnew, R. and Brezina, T. (2012) Juvenile Delinquency: Causes and Control. Oxford University Press, New York.

[2] Obioha, E.E. and Nthabi, A.M. (2011) Social Background Patterns and Juvenile Delinquency Nexus in Lesotho: A Case Study of Juvenile Delinquents in Juvenile Training Centre (JTC), Maseru. Journal of Social Sciences, 27, 165-177. https://doi.org/10.1080/09718923.2011.11892917

[3] UN (2005) Human Rights and Prisons. Manual on Human Rights Training for Prison Officials. New York and Geneva.

[4] Shoemaker, D.J. (1990) Theories of Delinquency. 2nd Edition, Oxford University Press, New York.

[5] Turner, J.H. (1975) Marx and Simmel Revisited: Reassessing the Foundations of Conflict Theory. Social Forces, 53, 618-627. https://doi.org/10.2307/2576477

[6] Jacob, A. (2011) Economic Theories of Crime and Delinquency. Journal of Human Behavior in the Social Environment, 21, 270-283. https://doi.org/10.1080/10911359.2011.564951

[7] Shoemaker, D. (2005) Theories of Delinquency: An Examination of Explanations of Delinquent Behavior. 5th Edition, Oxford University Press, New York.

[8] Karimu, O.O. (2015) Criminal Behavior: Evaluation of Labeling and Conflict Perspectives. European Scientific Journal, 11, 1-14.

[9] Pfohl, S.J. (1994) Images of Deviance and Social Control: A Sociological History. McGraw-Hill, New York.

[10] Nathaniel, A. (2012) Labeling Theory and the Effects of Sanctioning on Delinquent Peer Association: A New Approach to Sentencing Juveniles. Perspectives, 4, Article 10.

[11] Miller, N.R. and Steiner, B. (2014) Juvenile Delinquency. In: Mitchell, M., Ed., The Encyclopedia of Theoretical Criminology, Blackwell Publishing Ltd., Hoboken, 1-5. https://doi.org/10.1002/9781118517390.wbetc030

[12] Agnew, R. (2015) Part III Explaining Delinquency. General Strain Theory and Delinquency. In: Krohn, M.D. and Jodi, Eds., The Handbook of Juvenile Delinquency and Juvenile Justice, John Wiley \& Sons, Inc., Hoboken, 239-256.

https://doi.org/10.1002/9781118513217.ch16

[13] Godinet, T.M. and Vakalahi, O.H. (2009) Conceptualizing Delinquency among Samoan Adolescents: An Integrative Model. Journal of Ethnicity in Criminal Justice, 7, 135-159. https://doi.org/10.1080/15377930902932459

[14] Britt, L.C. (2015) Control Theories and Crime. In: International Encyclopedia of the Social \& Behavioral Sciences, Volume 4, 2nd Edition, Elsevier, Amsterdam, 834-839. https://doi.org/10.1016/B978-0-08-097086-8.45047-6

[15] Brezina, T. and Agnew, R. (2015) Juvenile Delinquency Its Nature, Causes, and Control. In: Goode, E., Ed., The Handbook of Deviance, John Wiley \& Sons, Inc., Hoboken, 311-330. https://doi.org/10.1002/9781118701386.ch18

[16] Siegel, L.J., Welsh, B.C. and Senna, J.J. (2006) Juvenile Delinquency: Theory, Practice and Law. Thomson/Wadsworth, Belmont.

[17] Curcio, L.A., Knott, E.V. and Mak, S.A. (2015) Why Do Young People Engage in Delinquency and Problem Drinking? Views from Adolescents and Stakeholders. Australian Psychologist, 50, 350-361. https://doi.org/10.1111/ap.12118

[18] Miller, N.R. and Fagan, A.A. (2014) Delinquency Prevention. In: Albanese, J.S., Ed., 
The Encyclopedia of Criminology and Criminal Justice, John Wiley \& Sons, Inc., New York, 1-8. https://doi.org/10.1002/9781118517383.wbeccj094

[19] Levan, K. and Mackey, A.D. (2015) Prevention of Crime and Delinquency. In: International Encyclopedia of the Social \& Behavioral Sciences, 2nd Edition, Volume 18, Elsevier, Amsterdam, 877-882.

https://doi.org/10.1016/B978-0-08-097086-8.45012-9

[20] Maton, I.K. (2004) Community Psychology. In: Encyclopedia of Applied Psychology, Wiley, New York, Vol. 1, 421-428. https://doi.org/10.1016/B0-12-657410-3/00175-6

[21] Webster-Stratton, C., Reid, J.M. and Hammond, M. (2001) Preventing Conduct Problems, Promoting Social Competence: A Parent and Teacher Training Partnership in Head Start. Journal of Clinical Child \& Adolescent Psychology, 303, 283-302. https://doi.org/10.1207/S15374424JCCP3003_2

[22] Higgins, E.G. and Osborne, D. (2015) Self-Control Theory and Crime. In: International Encyclopedia of the Social \& Behavioral Sciences, 2nd Edition, Volume 21, Elsevier, Amsterdam, 481-485. https://doi.org/10.1016/B978-0-08-097086-8.45082-8 